\title{
Beleza é fundamental sim, mas é essa beleza que queremos?: a aparência feminina nas páginas do jornal feminista Mulherio
}

Beauty is fundamental, but is it this beauty that we want?: the feminine appearance on the pages of the feminist newspaper Mulherio

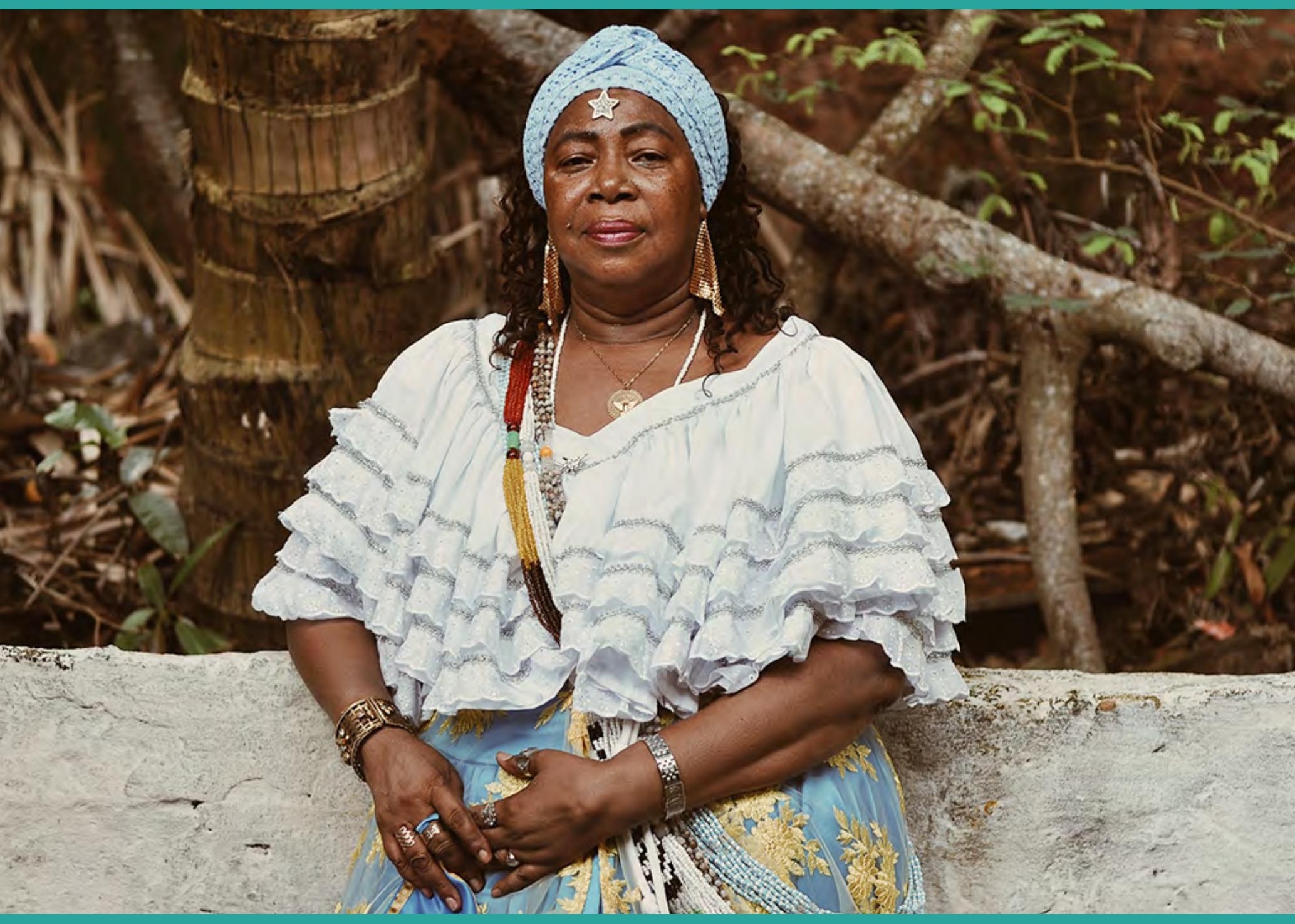




\section{Laise Lutz Condé de Castro ${ }^{1}$}

ORCID: https://orcid.org/0000-0001-7194-5704

[resumo] 0 presente trabalho investiga os registros acerca da aparência feminina veiculados na imprensa alternativa da década de 1980. Para esse artigo, escolheu-se o jornal Mulherio, que circulou entre 1981 e 1988 e foi um dos principais veículos feministas do Brasil. As análises apresentadas aqui são referentes às 23 edições que foram lançadas até o ano de 1985, período que encerra a Década da Mulher (1975-1985), fundada pela Organização das Nações Unidas (ONU). Tal momento foi fundamental na promoção de debates sobre a condição da mulher no Brasil e no mundo e pode ser considerado um hiato no qual os holofotes estiveram voltados para as reivindicações femininas.

[palavras-chave] Feminismo brasileiro. Imprensa feminista. Década da Mulher. Mulherio.

[abstract] The present work investigates the records of the female exhibition published in the alternative press of the 1980s. For this article the newspaper Mulherio, which circulated between 1981-1988 and was one of the main feminist press vehicles in Brazil, was chosen. The analyzes presented here refer to 23 editions that were launched until 1985, a period that ends the Decade of Women (1975-1985), founded by the United Nations Organization (UN). This moment was fundamental in promoting debates about the condition of women in Brazil and in the world and can be considered a period in which the spotlight was focused on women's demands.

[keywords] Brazilian Feminism. Feminist Press. Decade of Women. Mulherio.

Recebido em: 20-07-2020

Aprovado em: 19-08-2020

1 Doutoranda e Mestre pelo Programa de Pós-Graduação em Artes, Cultura e Linguagens da Universidade Federal de Juiz de Fora. E-mail: laiselutz1@hotmail.com. Lattes: http://lattes.cnpq. br/0861266036234236. 


\section{Introdução}

A aparência feminina, o ato de embelezar-se, há séculos é atribuída como uma questão fundamental da maioria das mulheres. Se adequar a um modelo de beleza proposto era necessário para conseguir um bom casamento e ainda é relevante mesmo após as conquistas feministas que modificaram estatutos ao redor do mundo. Sendo um dos principais componentes na construção da feminilidade hegemônica que norteia a vivência de mulheres ainda hoje, a beleza foi acrescentada na agenda de diversos movimentos feministas contemporâneos a fim de compreenderem melhor os problemas por trás de práticas tão naturalizadas. Porém, tais questões permanecem nebulosas. Dentro de um sistema consolidado a favor de uma lógica de poder masculina, transcender ideias há muito validadas parece um caminho inalcançável. Entretanto, os obstáculos não impediram que uma série de debates em torno do assunto fosse desenvolvida nos mais diversos grupos pelo mundo.

Nesse sentido, este artigo pretende abordar as relações entre a aparência e o feminismo por meio dos jornais da imprensa alternativa feminista que circularam no Brasil na década de 1980. Para tratar o tema, recorreu-se à análise do jornal Mulherio (1981-1988), editado na cidade de São Paulo. A partir de discussões em torno das especificidades femininas, o veículo foi um dos pioneiros nos debates do assunto. Outros jornais já abordavam questões referentes às mulheres na década de 1970, mas será a partir de 1980 que a temática aqui escolhida passará a ser tratada com maior profundidade. Os conteúdos analisados são referentes ao período de 1975 a 1985, definido pela Organização das Nações Unidas (ONU) como a Década da Mulher no mundo. Tal intervalo foi determinante para a promoção da condição feminina em países em desenvolvimento por meio de debates em fóruns e reuniões de grande visibilidade. No Brasil, que passava por uma ditadura militar, foi um momento crucial, pois criou espaços de discussão sem a tutela e a censura do governo.

Para este trabalho foram analisadas 23 edições do referido jornal que circularam entre 1981 e 1985, procurando por menções à aparência, à beleza, ao vestuário, à moda e à feminilidade, tanto nas matérias quanto na sessão das leitoras. A partir das palavras-chave, recortaram-se para esse momento alguns fragmentos a fim de explorarmos mais aprofundadamente os debates propostos pelas editoras. Ressalta-se que durante a década de 1980 houve maior incorporação das mulheres no mercado de trabalho, além das mudanças no cenário político brasileiro, com a chegada da Anistia e a abertura política. Tópicos antes considerados tabu passaram a ser abordados, como aborto, violência doméstica e sexualidade feminina. No entanto, aparência e beleza sempre foram assuntos de uma infinidade de publicações da imprensa feminina tradicional. Assim, é relevante destacar os discursos que pretendem apresentar-se na contramão da imagem hegemônica dos padrões burgueses de feminilidade fortemente propagada por essas revistas.

\section{"Beleza é fundamental" (?): relações entre feminismo e aparência}

"A beleza está para a mulher assim como a força compete aos homens" (SANT'ANNA, 2014, p. 17). Tal frase tão bem cunhada por Denise Sant'Anna define as relações e as preocupações que eram traçadas socialmente para cada gênero. Ainda que tenham sofrido algumas 
mudanças a partir da década de 1960, o percurso que levou as mulheres a se preocuparem constantemente em se adequar a determinados padrões de beleza e comportamento foi longamente delineado e consolidado.

Na modernidade, a aparência refletia um pertencimento a uma classe social (SIMMEL, 2008) e um estilo de vida que poderia ser ostentatório (VEBLEN, 1987). Anteriormente, no Antigo Regime, os trajes permitiam ornamentos e excessos na aparência para os dois sexos, em prol de uma legitimação do estilo aristocrático por meio do luxo. A partir da Revolução, mais precisamente com a chegada do século XIX, ocorreu a delimitação das fronteiras de gênero, com o belo sendo associado ao feminino, enquanto o masculino rejeitava qualquer resquício de frivolidade para assumir a austeridade exigida. 0 homem burguês, que habitava a vida pública, passou a se apoiar nos ternos, gravatas e cartolas de tons neutros que lhe davam dinamicidade e eficiência para aquele novo contexto. Já as mulheres continuaram preteridas ao privado, com suas roupas adornadas e nada práticas (HARVEY, 2003; LIPOVETSKY, 1999).

Excluídas do mundo do trabalho e de outras possibilidades sem a tutela masculina, Simmel (2008) considera que as mulheres dependiam fortemente da moda como trunfo social. Diante da frágil posição em que se encontravam na sociedade, buscavam se associar à conformidade, a formas de existência aprovadas por uma grande parcela da população. Pela imitação de modelos hegemônicos, conseguiam transitar mais tranquilamente em espaços públicos, seguras de estarem de acordo com o decoro em um período no qual não se admitia o mínimo erro. Além disso, confinadas ao âmbito doméstico, as mulheres da burguesia se moviam entre possibilidades muito restritas de modificar seu estatuto, com raras chances de demonstrarem sua individualidade em outros domínios sociais, diferentemente dos homens, que se sobressaíam por causa de suas profissões ou façanhas. Dessa forma, a moda transformou-se em uma área na qual era possível, também, se distinguir, exibindo traços de personalidade.

Portanto, torna-se compreensível que muitas mulheres passem a considerar a aparência como uma questão fundamental para a sobrevivência em sociedade, graças ao seu valor no mercado de bons casamentos, já que por muito tempo foram negligenciadas na conquista de outros domínios sociais. Essa relação de dependência foi tão bem arquitetada que permaneceu sólida mesmo após a conquista de novos espaços e possibilidades de vivências múltiplas.

Para Lipovetsky (1999), a partir da década de 1960, veremos uma abertura da moda, com um caráter muito menos coercitivo do que antes. Porém, no que tange à beleza física feminina, houve uma exacerbação da sua força de imposição, universalizando uma vigilância escrupulosa de sua imagem em função de paradigmas reconhecidos. Com a ascensão do neoindividualismo, o autor argumenta que, mesmo com as novas práticas corporais aplicadas para todos os indivíduos, ainda era possível reconhecer a diferença no seu impacto para as mulheres. Enquanto os homens demonstravam pouco interesse pelos detalhes de sua imagem, investindo em um corpo que transparecesse principalmente boa forma e saúde, para as mulheres, esse olhar tornou-se cada vez mais fragmentado e punitivo. 
Investe-se em todas as regiões do corpo; o narcisismo analítico detalha o rosto e o corpo em elementos distintos, cada um deles afetado por um valor mais ou menos positivo: nariz, olhos, lábios, pele, ombros, seios, quadris, nádegas, pernas são objeto de uma autoapreciação, de uma autovigilância que acarretam "práticas de si" específicas, destinadas a valorizar e a corrigir tal ou tal parte do físico. (LIPOVETSKY, 1999, p. 117)

Salientando isso, é compreensível que muitas feministas começassem a perceber as questões de embelezamento como uma amarra traçada por um sistema patriarcal-capitalista. Naomi Wolf (1992), por exemplo, considera que a sociedade ocidental utiliza das práticas de embelezamento para controlar as mulheres, principalmente após o fortalecimento dos movimentos feministas em vários lugares do mundo. Para Wolf (1992), elas conseguiram se libertar da mística feminina de Betty Friedan ${ }^{2}$ com o avanço das reivindicações sociais, porém, fez-se necessário instaurar uma nova forma de controle social desenvolvida pelo poder institucional masculino: a mística em torno da beleza.

A reação contemporânea é tão violenta, porque a ideologia da beleza é a última das antigas ideologias femininas que ainda tem o poder de controlar aquelas mulheres que a segunda onda do feminismo teria tornado relativamente incontroláveis. Ela se fortaleceu para assumir a função de coerção social que os mitos da maternidade, domesticidade, castidade e passividade não conseguem mais realizar. Ela procura neste instante destruir psicologicamente e às ocultas tudo de positivo que o feminismo proporcionou às mulheres material e publicamente. (WOLF, 1992, p. 13)

A utilização da ideologia da beleza é tão efetiva no combate à ascensão feminina que, considera-se aqui, não ocorreu somente com os avanços "pós-feministas", como salienta Wolf. Percebe-se seu acionamento desde o surgimento dos feminismos organizados politicamente, tanto no Brasil quanto no mundo. No caso brasileiro, que é o foco deste estudo, a aparência foi uma das principais armas utilizadas constantemente para enxovalhar as militantes em prol dos direitos femininos durante o sufrágio. Criou-se e difundiu-se, por meio da imprensa, o estereótipo dessas mulheres como feias, mal-amadas, masculinizadas.

\footnotetext{
2 Em 1963, Betty Friedan, frustrada com sua vida de mãe e dona de casa, começou a questionar porque esse sentimento era algo que atingia muitas mulheres americanas. Formada em jornalismo, ela realizou uma minuciosa pesquisa com cerca de 200 mulheres. Os resultados apontaram que as estadunidenses não se reconheciam na imagem da mulher moderna amplamente divulgada pelas revistas femininas. Ela nomeou essa figura inalcançável de "mística feminina". Tratava-se de mulheres educadas, lindas, sadias, que mantinham sua dedicação exclusiva ao marido, aos filhos e à casa, sendo essa a sua grande realização. Ainda contavam com a autonomia de fazer as compras da casa e de serem sempre amparadas por utensílios domésticos, diferentemente de suas mães e avós (FRIEDAN, 1971). Após lançar sua obra homônima, Friedan passou a ser considerada uma das grandes referências teóricas nos grupos feministas dos EUA.
} 
De acordo com Mayra Castro (2012), era possível encontrar caricaturas retratando-as como mulheres-homens em revistas do começo do século XX no Brasil, como a Eu sei tudo e Careta. Essa rotulação se desenvolveu junto com a luta feminina pela representatividade política, tornando-se mais atuante nos momentos de maior visibilidade. Tais depreciações também foram encontradas na imprensa alternativa, como foi o caso de charges produzidas por Ziraldo, que integravam o jornal $O$ Pasquim ${ }^{3}$, um dos principais veículos de oposição ao regime militar.

Rachel Soihet (2006) denuncia algumas dessas caricaturas em seu artigo Preconceito nas charges de $O$ Pasquim. Nas imagens selecionadas por Soihet, percebe-se que Ziraldo ironizava outros temas, como o fato de muitas militantes pertencerem à alta sociedade, atuando por causas que desconheciam, porém seu principal alvo para deslegitimá-las era a aparência, ou a distância dessas agentes do ideal de beleza exaltado pelo chargista. Em um dos exemplos analisados pela autora, publicado no Jornal do Brasil em 1980, conseguimos visualizar essa questão:

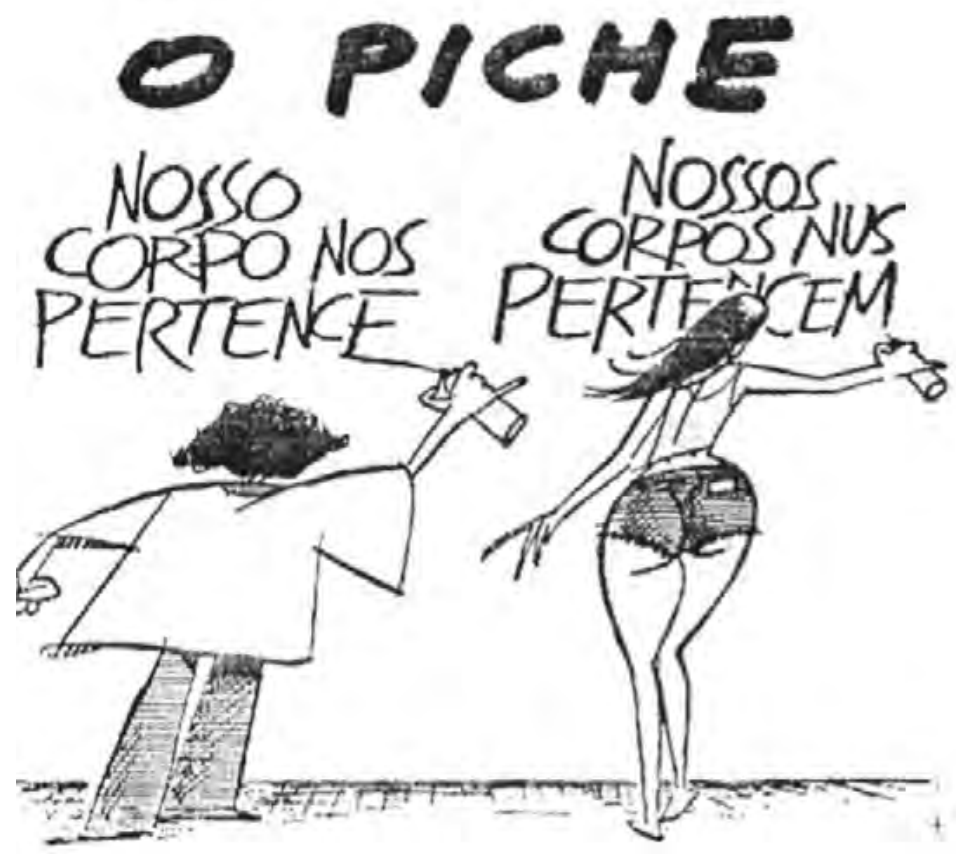

FONTE: SOIHET, Rachel. Preconceitos nas charges de $O$ Pasquim: mulheres e a luta pelo controle do corpo. ArtCultura, v. 9, n. 14, 2009, p. 50. Imagem obtida mediante impressão de tela do artigo.

\footnotetext{
O Pasquim foi um jornal fruto da imprensa alternativa que circulou no país de 26 de junho de 1969 a 11 de novembro de 1991. Seu surgimento foi concomitante com o endurecimento do regime militar, fazendo com que fosse conhecido como um importante aliado na luta contra a ditadura.
} 
Na imagem, vemos a frase "Nosso corpo nos pertence", proferida por muitas feministas da época, sendo pichada no muro pela figura que se conclui ser a ativista, à esquerda. À direita, outra mulher picha um trocadilho com os dizeres: "Nossos corpos nus pertencem". Direta, a charge utiliza a aparência das duas como forma de provocação. 0 desenho à esquerda representa de maneira bastante masculinizada a militante, com traços retos e postura dura, agressiva. Os cabelos são curtos e as roupas evidenciam ainda mais a discrepância entre as duas imagens. 0 gestual leve da segunda mulher sugere a delicadeza, bem distante da pose rígida da primeira. As curvas, as roupas e os cabelos, todos são signos de feminilidade introjetados socialmente. Ressalta-se que os traços mais delineados/curvilíneos e as palavras pichadas por essa figura evidenciam a preferência do autor por um modelo feminino vigente no imaginário masculino que coloca a mulher como objeto de desejo alienado à vontade dos homens. Isso é ainda mais notável pelos dizeres da imagem "Nossos corpos nus pertencem".

Castro (2012) salienta que mesmo quando a imprensa feminina apoiava os movimentos em prol das mulheres, como nas revistas Nova, Mais e Claudia, a aparência era constantemente abordada. Mas por outro viés, exaltando a beleza de algumas feministas como uma forma de negação do estereótipo.

Exemplo disso é reportagem com foto em Mais sobre Germaine Greer, uma modelo que se tornou feminista. 0 texto de chamada da reportagem diz o seguinte: "Feministas são mulheres frustradas, feias, 'masculinizadas', pensam muitos (e muitas). Mas Germaine Greer está aí para provar que não. E Jane Fonda, outra feminista, também (...)." Na foto, G. Greer está de biquíni, sentada, rindo, cabeça jogada para trás, cabelos compridos ao vento. Realmente nos passa a imagem de uma mulher feminina e feliz. Jane Fonda foi contemplada nesta matéria sob o mesmo enfoque: é possível ser bonita e ser feminista. (CASTRO, 2012, p. 113)

A autora cita outros exemplos e destaca: só era possível divulgar o feminismo nesses espaços tradicionais se as feministas reproduzissem uma aparência feminina. É concebível que houvesse um interesse em romper com os estereótipos que as deslegitimavam, afinal eram amplamente difundidos até mesmo nos ambientes de esquerda, como vimos no exemplo de Ziraldo. Mas, por outro lado, observa-se que não era interessante para os meios de comunicação destinados ao público feminino subverter com as questões referentes ao embelezamento. Grande parte do seu conteúdo era destinado à manutenção de tais práticas. Portanto, era atrativo ressaltar que algumas mulheres que se denominavam feministas também se preocupavam com o corpo, reproduziam uma feminilidade vigente, eram dignas de receberem destaque em um espaço que glamouriza, principalmente, a aparência hegemônica burguesa.

Fundamental recordar aqui que a imprensa dedicada ao público feminino conseguiu sobreviver mesmo com o avanço das lutas feministas, sem muitas rupturas em seus discursos, apenas adaptando-os para as novas gerações de mulheres mais críticas. De acordo com Denise Sant'Anna (1995), a partir dos anos 1960, com ascensão dos movimentos de contracultura e liberação do corpo, como o próprio feminismo, o discurso acerca da beleza sofreu uma reviravolta. As campanhas traziam a temática do cuidado com o próprio corpo, fazendo 
com que a ideia de sacrifícios para se embelezar cedesse espaço para o ideal em torno do prazer de se cuidar. A escalada do individualismo fez com que a indústria da beleza aprimorasse seus discursos, incorporando as bandeiras da liberdade em busca do prazer feminino (SANT'ANNA, 1995).

Justamente em razão dessa adaptação na forma de abordar a beleza, muitas revistas seguiram reproduzindo conteúdo derivado das bandeiras dos movimentos, mas mantendo suas modelos em um padrão estabelecido, destacando a importância do cuidado com o corpo, escolhendo feministas pontuais para receberem destaque em suas páginas. Esse esquema traz uma roupagem mais moderna às publicações, mas que, aprofundando, percebe-se que há uma forte indústria por trás, altamente adaptável, que transmite sutilmente para as leitoras: “Lute por seus direitos, mas esteja sempre bela!". E foi justamente na contramão dessas amarras tênues que as militantes da imprensa alternativa feminista brasileira discutiram a beleza em seus veículos.

\section{Analisando Mulherio: "Beleza é fundamental, sim. Mas é essa beleza que queremos?"}

O jornal Mulherio, escolhido para a análise neste trabalho, não foi o primeiro veículo da imprensa alternativa feminista no contexto da Década da Mulher, promovida pela ONU. É necessário rememorar brevemente dois anteriores que também surgiram com o objetivo de debater a condição feminina no Brasil: Brasil Mulher (1975-1980) e Nós Mulheres (1978-1980).

Produzidos em São Paulo e com circulação nacional, tiveram ao todo 17 e 8 números editados, respectivamente. Assim como muitos movimentos sociais que lutavam contra a ditadura no período, ambos seguiam uma referência ideológica marxista para pensar as relações de gênero. Com essa bagagem, logo definiram quem deveria ser o alvo de suas atenções: as mulheres trabalhadoras, principalmente as de camadas populares.

Os jornais acabavam privilegiando a luta de classes, deixando as questões em torno das especificidades femininas em segundo plano. Porém, é importante ressaltar, que essa era também uma estratégia de reconhecimento como grupo político.

\footnotetext{
Em suma, falando a linguagem marxista-masculina, as feministas esforçavam-se para dar legitimidade às suas reivindicações, para valorizar suas lutas e para se apresentarem como um grupo político importante, necessário e confiável. [...] Assim, articulavam-se para fora com os outros movimentos de luta pela redemocratização do país e eram legitimadas. (RAGO, 1996, p. 35)
}

Justamente pelo comando masculino ser comum nos movimentos de esquerda, muitas mulheres perceberam o machismo por trás de discursos que acusavam as militantes feministas de separatistas. Defendiam que a agenda em defesa da mulher deveria acontecer em um momento pós-revolução, caso contrário enfraqueceria o movimento (CARDOSO, 1984). Isto acabou afastando uma parcela de ativistas que tinham o intuito de aprofundar o debate em torno das particularidades do sujeito mulher, levando-as a seguirem novos rumos teóricos e políticos. 
Dessa forma, uma série de temas referentes à esfera privada que antes eram negligenciados nos debates por não pertencerem ao campo masculino, ganham destaque. Nesse momento, o viés teórico para a construção do que Rago (1996) denomina como "epistemologia feminista" começa a ser delineado, considerando as diferenças femininas como aspectos importantes para configurarem uma categoria sólida. 0 que passou a ser conhecido como "feminismo da diferença" se fundamenta nas teorias pós-modernas, buscando reconhecer o sujeito mulher como um grupo identitário4.

0 afastamento de uma visão puramente marxista-masculina, fez com que surgissem novos temas dentro da perspectiva dos movimentos feministas ${ }^{5}$. Antes colocados como tabu, até mesmo pelas próprias militantes, assuntos como as emoções e a moda foram desenvolvidos nesse campo conceitual emergente. Frisa-se também que, no início da década de 1980, o regime militar perdeu força e o Brasil caminhava para um processo democrático, abrindo espaço para novas discussões que já estavam latentes no panorama nacional. Bem articulado e consolidado, o feminismo brasileiro criará novas publicações abordando os problemas de gênero.

É nesse contexto que surge o jornal Mulherio, fruto da imprensa alternativa, que se manterá ativo de 1981 a 1988. Nascido da união de um grupo de pesquisadoras com o apoio da Fundação Ford ${ }^{6}$ e da Fundação Carlos Chagas 7 , o veículo, sediado em São Paulo, tinha periodicidade bimestral, oscilatória em alguns momentos. Era possível ser adquirido por meio de assinaturas e, segundo Amélia Teles (2017), comercializado em livrarias e distribuído por grupos e entidades. De circulação nacional, teve boa repercussão, chegando a possuir cerca de mil assinantes no terceiro número.

O conselho editorial era composto de "pesquisadoras, professoras e jornalistas engajadas na problemática feminista" (TELES, 2017, p. 101). Mariza Corrêa (2001) explica a ligação das editoras com as fundações de apoio:

\footnotetext{
${ }^{4}$ Para a melhor compreensão acerca do feminismo da diferença, consultar: IRIGARAY, Luce. A questão do outro. Labrys, Estudos Feministas, n. 1-2, 2002, p. 1-12. Disponível em: http://www. historiacultural.mpbnet.com.br/feminismo/irigaray1.pdf. Acesso em: 4 set. 2017. E DE OLIVEIRA, Rosiska Darcy. Elogio da diferença: o feminino emergente. Rio de Janeiro: Editora Rocco, 1991. E-book.

5 A chegada dessa nova perspectiva não anulou a existência de outras, apenas ampliou o leque de arcabouços teóricos no qual o feminismo pôde se apoiar. Como pontua Michelle Perrot (1991), só é possível falarmos de movimentos feministas no plural. Seus ideais e formas de atuação podem diferir, dependendo das condições sociais em que tais mulheres estão inseridas.

6 "A FF atua no Brasil desde 1962, e nos primeiros anos de sua atuação desempenhou um importante papel na carreira acadêmica de pesquisadores ameaçados pelo regime militar, pois forneceu bolsas individuais, principalmente aos acadêmicos." (ROCHA, 2017, p. 95)

Segundo o próprio site da instituição privada, a Fundação Carlos Chagas atua sem fins lucrativos e está empenhada na avaliação de competências cognitivas e profissionais e também na pesquisa na área de educação. A partir de 1971, com a criação do Departamento de Pesquisas Educacionais, a instituição passa a se dedicar às investigações interdisciplinares orientadas para a relação da educação com os problemas e perspectivas sociais do país.
} 
[...] a Fundação Carlos Chagas, tinha uma grande concentração de profissionais preocupadas com a situação da mulher, reunidas no Departamento de Pesquisas Educacionais sob a direção da psicóloga Carmen Barroso, já autora de alguns textos sobre o assunto, e lá se constituiu, com o apoio da Fundação Ford, um importante núcleo aglutinador de pesquisadoras e feministas. 0 primeiro concurso, que oferecia bolsas para pesquisar a situação da mulher no país, foi realizado em âmbito nacional em 1978 e continua a existir até hoje, agora com o apoio da Fundação MacArthur, e dirigido desde há alguns anos para o tema da saúde reprodutiva. Três anos depois de lançado o Concurso, a Fundação investiu também na criação de mais um jornal feminista, o jornal Mulherio. (CORRÊA, 2001, p. 18).

Corrêa informa ainda que o veículo tinha um caráter mais profissional que seus antecessores, trazendo matérias assinadas e uma equipe técnica definida. Muitos nomes do conselho editorial vieram do anterior Nós Mulheres, incluindo a própria autora 8 .

Sua trajetória é marcada por três fases específicas: a primeira delas durou até 1984, quando contou com o apoio das fundações Ford e Carlos Chagas. A partir de 1984, há a desvinculação da Fundação Carlos Chagas por questões burocráticas, provocando uma diminuição da periodicidade do jornal. Já em 1988, a publicação muda de título para Nexo, Feminismo, Informação e Cultura, perdendo o enfoque feminista e abrindo-se para outras abordagens.

Tendo as particularidades de gênero como seu escopo, logo no editorial, Mulherio deixa claro seu posicionamento e suas intenções. Pela leitura, é nítida a ideia de revitalizar a categoria feminina, procurando romper com as associações de feminino ou feminismo como algo depreciativo, recuperando a "[...] dignidade, a beleza e a força que significam as mulheres reunidas para expor e debater seus problemas [...]". . A palavra mulherio, utilizada como um termo pejorativo para denominar um conjunto de mulheres, já é um modo encontrado de fazer tal inversão de valores.

Esse viés ideológico, que se aproxima deveras do feminismo da diferença destacado mais acima, fez com que o jornal dedicasse um espaço importante para as discussões da aparência e da feminilidade. Até então, essas temáticas eram inexpressivas dentro de outros veículos como o Brasil Mulher e o Nós Mulheres. Dessa forma, analisar as páginas de Mulherio em busca das abordagens das militantes torna-se enriquecedor para compreender um campo que até os dias atuais continua confuso.

\footnotetext{
8 Durante o período de 1981 a 1985 analisado aqui, Adélia Borges foi a jornalista responsável por todos os 23 números. Foi também a editora principal ao lado de Fúlvia Rosemberg de 1981 a 1983. Além delas, o jornal contava ainda com mais 15 editoras fixas (Carmen Barroso, Carmen da Silva, Cristina Bruschini, Elizabeth Souza Lobo, Eva Alterman Blay, Heleieth Saffioti, Lélia Gonzalez, Maria Carneiro da Cunha, Maria Malta Campos, Maria Moraes, Maria Rita Kehl, Maria Valéria Junho Pena, Marília de Andrade, Mariza Corrêa e Ruth Cardoso) e com um time de colaboradoras convidadas a cada edição, como foi o caso de Leda Beck e Célia Chaim, que redigiram matérias que serão exploradas adiante. A partir do número 15, Inês Castilho entra na edição, porém, do 18 ao 23, a equipe começou a aparecer sem as funções estabelecidas para cada uma. 0 esquema de colaboradoras convidadas permaneceu.

9 Por que Mulherio? Mulherio, n. Ø. São Paulo, março/abril de 1981.
} 
Feita a apresentação, inicia-se as análises a partir da carta de uma leitora intitulada "Lutar, mas também amar e ser feliz". Nela, a militante da Frente Feminista 4 de janeiro, da cidade de Fortaleza (CE,) Verônica Guedes, faz uma queixa pela forma com que as partidárias de esquerda tratam as mulheres que priorizavam as questões de gênero.

\begin{abstract}
$\mathrm{Eu}$, como tantas outras mulheres, cheguei ao movimento feminista oriunda dos movimentos políticos mais gerais. Cheguei, como tantas outras, com todas as dificuldades em reconhecer e assumir 'o pessoal' como político, tateando uma vivência de descobertas incríveis. Era como se no meu armário o tempo todo tivesse a minha disposição uma linda roupa colorida com poderes de me fazer amar a vida, a natureza e ao próximo, sem perder a minha identidade de mulher e eu preferisse optar por uma velha roupa cinzenta com uma enorme cruz pregada nas costas, em nome de uma vida, um amor e um futuro não muito próximos e com uma identidade assexuada. Na prática, no entanto, as coisas não se apresentam com a simplicidade de uma metáfora. As próprias companheiras que num passado recente nos tratavam com todo respeito que "um político deve ter por outro político", nos ridicularizam como se estivéssemos nos vestindo de "bobas da corte". E por quê? Temos colocado insistentemente a necessidade de no movimento feminista se lutar pelas questões femininas, tendo o cuidado de não trazer para os grupos feministas as disputas de tendência. Mas esbarramos no preconceito, na desconfiança e no descaso com que considerável parte da esquerda brasileira trata "as questões pessoais" e que nós chamamos de específicas. Não pensamos em trocar fuzis por flores, nem abrimos mão de lutar por uma sociedade humana e justa. Queremos participar da construção dessa nova sociedade, mas queremos também amar, ser felizes e alegres com a mesma intensidade com que sofremos pela nossa trágica realidade social e, para isso, precisamos de uma identidade, de nossa identidade de mulher-sexo feminino e não de uma triste militância assexuada ${ }^{10}$. (GUEDES, 1981, p. 2)
\end{abstract}

Nota-se que a aparência era uma questão fundamental para ambas as partes. De um lado, Verônica, que considerava o ser "feminina" como algo intrínseco à sua identidade de mulher, sendo crucial para afirmá-la como sujeito distinto. De outra parte, as mulheres filiadas aos partidos de esquerda também consideravam a questão, mas com outro viés. Era indispensável para elas recusar um visual hegemônico, identificado com a aparência burguesa. Dentro desses ambientes, essa imagem deveria ser evitada a todo custo. Conforme Verônica afirma, as feministas não partidárias eram consideradas como "bobos da corte", alguém que se movimenta de acordo com o sistema.

Mas é imprescindível recordar que os partidos eram espaços majoritariamente masculinos, como mencionado anteriormente. Isso faz com que a busca pela "assexualidade",

10 GUEDES, Verônica. Lutar, mas também amar e ser feliz. Mulherio, n. 3. São Paulo, setembro/ outubro de 1981. 
não só da aparência, como é colocada na carta, seja uma estratégia de aceitação, uma procura pela paridade, mesmo que visual. É destacável que Verônica critica a anulação do "feminino" dentro desses espaços, com uma metáfora muito bem empregada, alusiva ao próprio universo da feminilidade, tão constantemente associado como algo frívolo e aburguesado. Para ela, o feminino é um campo de possibilidades que deve ser explorado, não apagado.

0 apreço de Mulherio ao tema aqui explorado tornou-se mais evidente com a publicação de um número completo dedicado ao assunto. 0 jornal abordou algumas problemáticas das indústrias da moda e da beleza, demonstrando as limitações impostas às mulheres por um sistema patriarcal-capitalista.

Em Espelho, espelho meu ${ }^{11}$, Leda Beck utiliza um compilado de entrevistas feitas com homens e mulheres pelas ruas, na busca de compreender o que é uma mulher bela na concepção do brasileiro. De início, ela percebe que o tipo feminino mais comentado é o da mulher loira de olhos claros, como a atriz Bruna Lombardi, que nesse momento estava em destaque na televisão. Necessário frisar que esse padrão era amplamente difundido e valorizado pelos meios de comunicação, mas estava e está muito distante da realidade do país.

Após isso, Beck entrevista uma moça com as mesmas características da atriz mencionada, porém destaca que, para a jovem, ia além de ter um biotipo mais europeu. Não bastava apenas ser loira de olhos claros, mas possuir um conjunto de elementos que colaboravam para a construção de uma imagem ideal. Tudo isso se dava com processos de embelezamento que custavam caro para as mulheres no geral: "Pois os ricos podem recorrer a todos os artifícios da indústria da beleza: os modelos, assim, condicionam as pessoas, e muito especialmente as mulheres, aos interesses econômicos do sistema"12 (BECK, 1982, p. 12). Dessa forma, a jornalista procura esclarecer para a leitora como tal esquema lucra com a criação de padrões de beleza pré-estabelecidos, que resulta em um investimento de tempo e dinheiro em busca de adequação, sendo as mulheres o principal alvo. Enfatiza ainda que para as pessoas de grande poder aquisitivo, os produtos oferecidos pela indústria da beleza são mais acessíveis. Sendo assim, a mulher rica se torna referência para as mulheres das camadas populares que, por conseguinte, devem lutar para alcançar um modelo inatingível.

De acordo com Beck, as maiores propagadoras de modelos para as mulheres brasileiras são as telenovelas. Difundem cotidianamente nos televisores um tipo de beleza branco, esguio e impecável, que mesmo quando se tem personagens femininas emancipadas, com uma dupla jornada de trabalho, a aparência das atrizes permanece glamourosa. Ela cita o exemplo da personagem Luiza, da novela Brilhante (1981), interpretada pela atriz Vera Fischer:

"Luíza" é a mulher perfeita para a sociedade de consumo: além de bonita, também é uma mulher emancipada, que se veste simplesmente - mas sempre na moda e com muito charme - se maquia com suavidade. Despedida do emprego, abandonada pelo homem de sua vida, nunca perde o bom humor: conserva to-

\footnotetext{
11 BECK, Leda. Espelho, espelho meu. Mulherio, n. 5. São Paulo, janeiro/fevereiro de 1982.

12 BECK, Leda. Espelho, espelho meu. Mulherio, n. 5. São Paulo, janeiro/fevereiro de 1982.
} 
das as qualidades da clássica esposa-e-mãe, é compreensiva, carinhosa, alegre e terna. Nunca está suada, despenteada, com a maquiagem borrada, nem no fim de um exaustivo dia de trabalho e grandes emoções ${ }^{13}$. (BECK, 1982, p. 12)

Abre-se aqui um parêntese para recorrer à teoria de Teresa de Lauretis (1994) sobre o que ela nomeia como "tecnologias do gênero". A autora define que essa construção se dá por meio de várias técnicas, como o cinema e os discursos institucionais que possuem a capacidade de controlar o campo do significado social a fim de "produzir, promover e implantar' representações de gênero" (LAURETIS, 1994, p. 228). Como as telenovelas eram, naquele momento, o produto midiático mais consumido pelos brasileiros, é possível reconhecer que elas, até mais do que o cinema, são responsáveis por disseminar modelos capazes de auxiliar na reiteração de um padrão hegemônico. Sendo assim, ao impor arquétipos que beiram o irreal, mas que rendem lucros aos patrocinadores desses programas, criam um ideal nocivo e inatingível que causa frustração.

Beck continua salientando que, para as mulheres, há um grande impasse: "Como coordenar autoestima e exigência social?" (BECK, 1982, p. 13). Para a jornalista, a questão é justamente o fato de o rosto e o corpo feminino estarem em constante busca de emulação, em vez de um reconhecimento de sua essência. "Parecem o que não são para corresponder a modelos de beleza que são sinônimos de valorização social - admiração, prestígio, sucesso, amor. A ordem é fazer-de-conta que"14 (BECK, 1982, p. 13). Isso evidencia a necessidade de corresponder a uma exigência social. Como Simmel (2008) destaca, é pela imitação que as mulheres conseguem se sentir seguras para circular em uma sociedade que as examina e as classifica frequentemente. Ainda que a rigidez do século XIX e do início do XX, período de análise do autor, não comande a década de 1980, a aparência feminina ainda é uma obrigação. Agora, não apenas para arranjar um casamento ou exibir a fortuna de seu marido, mas para garantir um bom emprego e ter respeitabilidade.

0 texto prossegue e se observa que a lógica da beleza atinge as próprias feministas que reconhecem os problemas desse esquema, enfrentando dificuldades de irem na contramão, visto a complexidade de conceitos introduzidos por séculos. Beck cita o exemplo de uma militante que relata: "A gente discute e tal, mas a gente também não quer ser um buxo, né? Nós todas, mulheres, estamos muito presas ao padrão"15 (BECK, 1982, p. 13). Esse trecho revela como o processo de desconstrução dessa relação é ardiloso. A aparência surge para a entrevistada como uma questão debatida, entretanto, parece não avançar na prática. Wolf explica:

\footnotetext{
13 BECK, Leda. Espelho, espelho meu. Mulherio, n. 5. São Paulo, janeiro/fevereiro de 1982.

${ }^{14}$ BECK, Leda. Espelho, espelho meu. Mulherio, n. 5. São Paulo, janeiro/fevereiro de 1982.

15 BECK, Leda. Espelho, espelho meu. Mulherio, n. 5. São Paulo, janeiro/fevereiro de 1982.
} 
Pesquisas recentes revelam com uniformidade que em meio à maioria das mulheres que trabalham, têm sucesso, são atraentes e controladas no mundo ocidental, existe uma subvida secreta que envenena nossa liberdade: imersa em conceitos de beleza, ela é um escuro filão de ódio a nós mesmas, obsessões com o físico, pânico de envelhecer e pavor de perder o controle. (WOLF, 2006, p. 12)

Caminhando para sua conclusão, a reportagem questiona sobre a possibilidade de romper com um sistema hegemônico. Para Beck, é possível não uma ruptura completa, mas criar fissuras que desestabilizam a sólida estrutura.

A chave deve estar por aí, exercer o poder de seleção sobre os modelos e não se deixar usar por eles, não ser apenas um manequim desengonçado na passarela social. Porque a Twigg é a Twigg, mas eu sou eu e você é você. E nenhuma de nós poderá ter o rosto da outra ${ }^{16}$.(BECK, 1982, p. 13)

Essa reflexão está em compasso com o que Elizabeth Wilson (1989) disserta em seu livro Enfeitada de sonhos. Nele, a autora menciona que muitas feministas tentaram romper com o sistema da moda, mas que essa tarefa é impossível. Porém, ao empenhar-se em tal função, se esquivaram, criaram novos caminhos, desenvolvendo novas possibilidades de se vestir e se comportar, tencionando as fronteiras de poder entre homens e mulheres. Na reportagem, Beck reconhece as dificuldades de subverter um esquema bem articulado. Procurando demonstrar para as leitoras que tais modelos não deixarão de existir, ela sugere que se desenvolva ao menos uma crítica sobre eles e os utilize a seu favor, em vez de simplesmente absorvê-los como manequins inanimados como pretende o sistema.

Ainda nesse número, Maria Rita Kehl, no artigo intitulado Beleza é fundamental, sim, propõe também uma subversão de conceitos. Em seu texto, questiona a diferença entre as perspectivas de mulheres e homens.

Mas mesmo quando a mulher olha o homem, ainda se coloca uma questão: o que é que ela vê? Vê a beleza, sim - sobretudo aquela que emana da sensualidade, às vezes da doçura, da sensibilidade. Se é que a repressão tem alguma consequência vantajosa, posso pensar que no caso dos valores envolvidos no mercado sexual de nossa sociedade, o fato da mulher ser mais reprimida como conquistadora nos permitiu tempo e espaço para ver, no homem, outras coisas. Se os homens afirmam que vêem na mulher antes de mais nada "belos contornos", considero isso como um empobrecimento de sua capacidade de olhar e ver. Estou convencida de que nosso olhar sabe encontrar no homem sinais do que ele é, além dos contornos de sua musculatura ${ }^{17}$. (KEHL, 1982, p. 14)

\footnotetext{
${ }^{16}$ BECK, Leda. Espelho, espelho meu. Mulherio, n. 5. São Paulo, janeiro/fevereiro de 1982.

${ }^{17}$ KEHL, Maria Rita. Beleza é fundamental, sim. Mulherio, n. 5. São Paulo, janeiro/fevereiro de 1982.
} 
Esse trecho reafirma como os homens não dependem da beleza como trunfo para o sucesso. Suas habilidades e seus traços de personalidade costumam ser valorizados pelas mulheres. De acordo com Kehl, para eles, a aparência feminina é característica fundamental, como se encontra com frequência tal afirmação em canções ou na literatura, por exemplo. Isso se dá porque nossa cultura definiu há séculos que os homens são dignos de complexidade, enquanto as mulheres são relegadas ao belo, à admiração. Nossa cultura visual desenvolveu uma noção do feminino como objeto de mera contemplação, e não agenciamento, ou seja, como objeto passivo, à espera da ação masculina, da sua admiração. Laura Mulvey (1983) define bem essa relação:

A mulher, desta forma, existe na cultura patriarcal como o significante do outro masculino, presa por uma ordem simbólica na qual o homem pode exprimir suas fantasias e obsessões através do comando linguístico, impondo-as sobre a imagem silenciosa da mulher, ainda presa a seu lugar como portadora de significado e não produtora de significado. (MULVEY, 1983, p. 438)

Ao final de sua análise, Kehl destaca:

No entanto, depois de tudo isso continuo concordando com uma parte da frase opressiva do poeta: 'beleza é fundamental'. 0 que propomos não é o elogio da feiura, a ideologia do 'quanto mais maltratada melhor' - e sim a subversão de nossos conceitos estéticos.

A maior beleza é a do corpo livre, desinibido em seu jeito próprio de ser, gracioso porque todo ser vivo é gracioso quando não vive oprimido e com medo. É a livre expressão de nossos humores, desejos e odores; é o fim da culpa e do medo que sentimos pela nossa sensualidade natural; é a conquista do direito e da coragem a uma vida afetiva mais satisfatória; é a liberdade, a ternura e a autoconfiança que nos tornarão belas. É essa a beleza fundamental ${ }^{18}$. (KEHL, 1982, p. 14)

Para a jornalista, a beleza é algo que deve transcender a aparência física, deixando de ser um fardo para as mulheres, e sendo vista como apenas uma possibilidade. 0 desafio é se libertar para o mundo e também para si mesma em busca de uma vivência menos limitada, que vá além da preocupação com o outro, pensando em si como corpo agente, produtor de significado.

Na mesma edição, Mulherio apresenta Quem ganha quando a moda pega, de Célia Chaim. No texto, a autora denuncia como o sistema da moda é uma cadeia que viabiliza lucros sobre as frequentes mudanças a partir da especulação do corpo feminino, fazendo com que as mulheres lutem para acompanhá-las.

\footnotetext{
${ }^{18}$ KEHL, Maria Rita. Beleza é fundamental, sim. Mulherio, n. 5. São Paulo, janeiro/fevereiro de 1982.
} 
A receita é simples: cria-se um padrão de beleza e acionam-se os mecanismos de persuasão; os padrões mudam, a moda muda, oferecem-se novos produtos e o ciclo não para.

A prática mostra que não faltam mercadorias. Nem tendências e padrões que nos levam a cortar e encrespar os cabelos como mostra a atriz da novela das oito ou a andar fantasiados de esportistas como sugeriu a moda descontraída da revista feminina. Todos ganham quando a moda pega. [...]

[...] A modelo Márcia Valentim contou, numa de suas entrevistas, que era forçada a disfarçar suas sardas com grossas camadas de maquilagem para atingir o padrão de beleza de um modelo fotográfico. Esse padrão mudou e hoje são as sardas de Márcia que garantem a imagem de sensualidade. Quem decidiu? 0 mesmo sistema que, neste verão, determina calças pelo joelho, cores alarmantes, cabelos arrepiados. Para todas as mulheres, indistintamente ${ }^{19}$. (CHAIM, 1982, p. 15)

Ao desnudar esse esquema para a leitora, Chaim corrobora com o argumento anterior de Leda Beck sobre o lado nocivo das indústrias da moda e da beleza. São modelos temporariamente definidos para serem aplicados a todas as mulheres, que são ímpares. A preocupação exaustiva que algumas podem ter ao tentar se encaixar nos ditames da moda provoca um desapontamento quando surgem novas orientações que valorizam algumas características em detrimento de outras, como foi exemplificado pelas sardas da modelo.

Mesmo mulheres de grande sucesso em áreas tradicionalmente masculinas, como os esportes, não escapavam ao juízo da beleza. No número 16, uma reportagem sobre as atletas nas olimpíadas de 1984 destaca a jogadora de basquete Hortência Marcari, que estava em evidência no momento.

Hortência vem aparecendo muito ultimamente, dando mil entrevistas à imprensa. E com um discurso muito parecido com o das feministas: provar que, apesar de não ter seguido o modelo feminino, apesar de bem sucedida numa área masculina, é mulher.

"Nunca fui muito de usar vestidinho com babadinho, mas sempre me preocupei com a Hortência mulher. Fora da quadra sempre procurei mostrar o que tenho de mulher. Quando eu era pequena, ninguém pensava que eu era mulher. Todo mundo dizia que eu era homem. Mas isso nunca me humilhou porque eu gostava de mim do jeito que eu era, adorava jogar bola, não ligava. De repente, pintou esse lance de jogar basquete e todo mundo dizendo que jogadora de basquete era sapatão. Eu nunca liguei, porque não sou."

${ }^{19}$ CHAIM, Célia. Quem ganha quando a moda pega. Mulherio, n. 5. São Paulo, janeiro/fevereiro de 1982. 
Dia desses, pra mostrar que mulher atleta não deixa de ser mulher - de gostar, por exemplo, de ficar bonita, preocupar-se com a aparência etc. - Hortência deixou-se filmar pela TV Globo, junto com Suzete, também da Seleção, indo a um cabeleireiro em São Paulo. A reportagem, feita pela única repórter de esportes da Globo em SP, Kitty Baleeiro, ficou bonita demais: ao som de uma música de Joyce, "Feminina", Hortência e Suzete davam um tempo da puxada concentração para arrumar o cabelo, se maquiar, essas coisas. Pois não é que, depois que a reportagem passou, o apresentador do programa, Osmar Santos, saiu com uma de doer? Ele disse algo do tipo: "Essas meninas jogam uma bola que não é fácil, mas elas são feinhas, feinhas...". 0 "feinha" doeu fundo nas duas, que no dia seguinte responderam: "Garotinho, você pisou na bola..." ${ }^{20}$. (BORGES, 1984, p. 15)

A matéria começa dizendo que, assim como as feministas, Hortência necessita constantemente de se provar mulher. Recordando o estereótipo que foi mencionado aqui em torno das militantes, é possível reconhecer a importância que o jornal dava a essa afirmação. Porém, como se prova que é mulher? Para Hortência, e também para Mulherio, o embelezamento aparece como algo fundamental. Mesmo havendo uma recusa por parte da jogadora em usar um guarda-roupa visto como romântico, fica evidente essa questão quando a reportagem narra a ida de Hortência e Suzete ao salão. Na frase “(...) para mostrar que mulher atleta não deixa de ser mulher - de gostar, por exemplo, de ficar bonita, preocupar-se com a aparência etc.", o jornal associa o ato de embelezar-se a uma característica intrínseca ao feminino.

Ressalta-se como as táticas de legitimação da feminilidade se pautam especificamente pela aparência, na maioria dos casos. É a forma de reação mais direta encontrada também pelas editoras para responder a um estereótipo da feminista consolidado no imaginário social. Embora abordem em suas páginas a necessidade de desconstrução de uma categoria considerada opressora, acabam caindo na armadilha de celebrar o feminino hegemônico como estratégia de afirmação, semelhante às revistas rememoradas por Mayra Castro (2012).

Tal questão é tão importante que vemos o incômodo com a frase dita pelo apresentador. Ser chamada de "feinha" não é um problema para os homens, inclusive, são raros os comentários sobre a aparência de personalidades masculinas, sobretudo nesse momento. Porém, quando se volta para as mulheres, é algo que fere intimamente, pois se trata de um dever, uma obrigação. Mesmo quando se é uma jogadora de basquete com inúmeras conquistas, a beleza é usada como arma para desqualificar. E consegue. Destaca-se também nessa matéria que ter uma postura de esquerda não anulava o machismo. 0 apresentador que insulta Hortência e Suzete era Osmar Santos, o locutor do movimento Diretas Já! ${ }^{21}$. Isso

\footnotetext{
20 BORGES, Adélia. De Atenas a Los Angeles. Mulherio, n. 16. São Paulo, maio/junho de 1984.

${ }^{21}$ Osmar Santos era locutor e animador dos comícios que aconteceram por todo país em prol das Diretas Já!. Tais eventos contavam com a presença de artistas, políticos e intelectuais pedindo a realização de eleições diretas no Brasil no ano de 1984.
} 
reforça o que Soihet menciona em suas análises de $O$ Pasquim e o que muitas feministas já vinham denunciando no fim da década de 1970.

\section{Considerações finais}

0 presente trabalho analisou alguns registros encontrados em relação à aparência feminina no jornal Mulherio. De fato, as críticas feitas pelo veículo à opressão sofrida pelas mulheres por meio da padronização dos corpos se mostram um pouco ambíguos em alguns momentos. Denunciam os processos de embelezamento, como na edição destinada ao tema, mas celebram quando esses são utilizados como estratégia de afirmação da categoria mulher. Dessa forma, não fica mensurável a importância dada à aparência e seus processos, visto que desejam subverter a feminilidade hegemônica, mas acabam definindo o feminino pelas práticas de beleza consolidadas no imaginário social.

Entretanto, é relevante mencionar que o jornal possuía um corpo editorial grande e distinto. Apesar de ser editado por duas a três jornalistas responsáveis, geralmente contava com 15 editoras, alternando os nomes durante sua existência. Além disso, publicava também matérias de jornalistas colaboradoras, como Leda Beck e Célia Chaim, que apareceram nas análises deste trabalho. Tal variedade de escritoras pode explicar porque, em alguns momentos, surgiram pensamentos conflitantes acerca das temáticas abordadas.

No entanto, como cobrar uma posição completamente coerente do tema se, mesmo no século XXI, com um retorno feroz das bandeiras feministas, tal questão ainda é amplamente debatida e permanece em aberto? Se, em plena campanha eleitoral de 2018 do então candidato à presidência da República, Jair Bolsonaro, vimos ser proferida por um de seus filhos, o deputado federal Eduardo Bolsonaro, a frase "Mulher de direita é mais bonita e higiênica que a de esquerda"22? Nota-se que discursos como esse, que utilizam da aparência a fim de depreciar a mulher que se denomina pró-feminismo ou, no caso, contrárias aos avanços conservadores que assolam o país, não perderam espaço. Ao contrário, permanecem e ainda são eficazes, pois levaram a uma mobilização nas redes sociais nas quais muitas militantes se defenderam postando suas fotos para provarem ser belas.

E mesmo com a progressão de movimentos feministas em várias partes do mundo, a indústria da beleza recrudesce, tornando-se cada vez mais um gênero de primeira necessidade. "Das sobrancelhas à genitália, tudo no corpo tornou-se objeto de embelezamento diário" (SANT'ANNA, 2014, p. 15). Vivemos a época em que se submeter a cirurgias estéticas, ingerir medicamentos e ter uma disciplina alimentar são considerados aspectos aceitáveis para alcançar a almejada autoestima, mesmo que isso despenda quantias significativas de dinheiro e tempo, além de riscos consideráveis à saúde.

Essas mulheres, ainda que lidando tortuosamente com questões nebulosas, apresentaram o que dificilmente seria discutido em outros veículos. Como destaca Dulcília Buitoni (1981), esses assuntos só poderiam ser abordados na imprensa alternativa feminista. Afi-

\footnotetext{
22 Disponível em: https://br.noticias.yahoo.com/mulher-de-direita-e-mais-bonita-e-higienica-que-de-esquerda-diz-filho-de-bolsonaro-135535648.html. Acesso em: 11 jul. 2020.
} 
nal, somente em um espaço não dependente de publicidades se teria abertura para criticar o que é difundido a todo o momento nos meios de comunicação.

Sendo assim, considera-se que Mulherio foi longe e quiçá pioneiro nas discussões em torno da crítica feminista às amarras da aparência feminina no Brasil. Mesmo sem respostas prontas, apresentou a problemática a uma parcela da população que poderia não ter acesso a tal conteúdo, explorando o objeto e procurando romper com estereótipos estabelecidos a fim de expor possibilidades de vivências menos compulsórias. Além disso, preparou o terreno para muitas feministas seguirem fomentando debates necessários que são cada vez mais abordados nos movimentos contemporâneos.

\section{Referências}

BUITONI, Dulcília Helena Schroeder. Mulher de papel: a representação da mulher na imprensa feminina brasileira. São Paulo: Edições Loyola, 1981.

CARDOSO, Elizabeth. Imprensa feminista brasileira pós-1974. Revista Estudos Feministas. Florianópolis, v. 12, 2004, p. 37-55. Disponível em: https://periodicos.ufsc.br/index.php/ ref/article/view/10222. Acesso em: 26 nov. 2018.

CASTRO, Mayra Corrêa. Feminismo prêt-à-porter: significação da aparência na imprensa feminina e feminista do Brasil. Cadernos AEL, Campinas, v. 2, n. 3/4, 1996, p. 111-152. Disponível em: https://www.ifch.unicamp.br/ojs/index.php/ael/article/view/2615. Acesso em: 14 ago. 2017.

CORREAA, Mariza. Do feminismo aos estudos de gênero no Brasil: um exemplo pessoal. Cadernos Pagu, Campinas, n. 16, 2001, p. 13-30. Disponível em: http://www.scielo.br/pdf/ cpa/n16/n16a02.pdf. Acesso em: 23 jul. 2017.

FRIEDAN, Betty. Mística feminina: o livro que inspirou a revolta das mulheres americanas. Trad. Áurea B. Weissenberg. Petrópolis: Vozes Limitada, 1971.

FUNDAÇÃO CARLOS CHAGAS. Disponível em: http://www.fcc.org.br/conteudosespeciais/ mulherio/historia.html. Acesso em: 5. jul. 2020.

HARVEY, John. Homens de preto. São Paulo: Editora Unesp, 2003.

LAURETIS, Teresa de. A tecnologia do gênero. In: HOLLANDA, Heloisa (org.). Tendências e impasses: o feminismo como crítica da cultura. Rio de Janeiro: Rocco, 1994, p. 206-242.

LIPOVETSKY, Gilles. 0 império do efêmero. São Paulo: Companhia das Letras, 1999. 
MULHERIO. São Paulo: S/A O Estado de S. Paulo, 1981-1988. Bimestral. Pesquisado em Arquivo Edgard Leuenroth - AEL - Unicamp. Acesso em: 21mar. 2017.

MULVEY, L. Prazer visual e cinema narrativo. In: XAVIER, Ismail (org). A experiência do cinema. Rio de Janeiro: Editora Graal: Embrafilme, 1983.

RAGO, Margareth. Adeus ao feminismo? Feminismo e (pós) modernidade no Brasil. Cadernos AEL,Unicamp v. 2, n. 3/4, 2012, p. 11-43. Disponível em: https://www.ifch.unicamp.br/ojs/ index.php/ael/article/view/2612/2022. Acesso em: 24 mar. 2017.

ROCHA, Ednéia Silva Santos. Contribuições da Fundação Ford à formação e consolidação de campos científicos no Brasil. InCID: Revista de Ciência da Informação e Documentação, São Paulo, publicação. 7, n. 2, 2017, p. 93-117. Disponível em: https://www.revistas.usp.br/ incid/article/view/110886/118528. Acesso em: 23 fev. 2018.

SANT’ANNA, Denise Bernuzzi. Políticas do corpo. São Paulo: Estação Liberdade, 1995 p. 81-114.

SANT’ANNA, Denise Bernuzzi. História da beleza no Brasil. São Paulo: Contexto, 2014.

SIMMEL, Georg. Filosofia da moda e outros e outros escritos. Lisboa: Edições Texto \& Grafia Ltda, 2008.

SOIHET, Rachel. Preconceitos nas charges de $O$ Pasquim: mulheres e a luta pelo controle do corpo. ArtCultura, Uberlândia, v. 9, n. 14, 2009. Disponível em: http://www.seer.ufu.br/ index.php/artcultura/article/view/1444. Acesso em: 14 fev. 2020.

TELES, Maria Amélia de Almeida. Breve história do feminismo no Brasil e outros ensaios. São Paulo: Editora Alameda, 2017.

VEBLEN, Thorstein. A teoria da classe ociosa: um estudo econômico das instituições. Trad. Olivia Krähenbühl. São Paulo: Abril Cultural, 1987.

WILSON, Elizabeth. Enfeitada de sonhos: moda e modernidade. Trad. Maria João Freire. Lisboa: Edições 70, 1989.

WOLF, Naomi. 0 mito da beleza. Trad. Waldéa Barcellos. Rio de Janeiro: Rocco, 1992.

"MULHER DE DIREITA É MAIS BONITA E HIGIÊNICA QUE DE ESQUERDA", DIZ FILHO DE BOLSONARO. Yahoo! Notícias. 1 out. 2018. Disponível em: https://br.noticias. yahoo.com/mulher-de-direita-e-mais-bonita-e-higienica-que-de-esquerda-diz-filho-debolsonaro-135535648.html. Acesso em: 11 jul. 2020. 